\title{
Qrevisto
}

ISSN n² 2447-4266 Vol. 3, n. 2, Abril-Junho. 2017

DOI: http://dx.doi.org/10.20873/uft.2447-4266.2017v3n2p92

\section{HISTÓRIA ESCOLAR, CINEMA BRASILEIRO E HISTÓRIA PÚBLICA: caminhos de uma memória}

SCHOOL HISTORY, BRAZILIAN MOVIES AND PUBLIC HISTORY: paths of a memory

HISTORIA ESCOLAR, CINE BRASILEÑO E HISTÓRIA PUBLICA:

los caminos de una memoria

\section{Vitoria Azevedo da Fonseca ${ }^{1,2}$}

\section{RESUMO}

A proposta deste texto é refletir sobre a presença da temática da história escolar no cinema brasileiro ao longo de sua trajetória, a partir de uma comparação entre as etapas da constituição da disciplina escolar e a produção cinematográfica. Observamos, no entanto, que, nos últimos dez houve um distanciamento entre a história no cinema e a historia escolar, considerando ter sido esta aproximação muito comum em outros períodos históricos. Isso pode indicar, no entanto, que a temática histórica no cinema vem sendo ampliada para outros públicos e outros espaços deixando de ser pensada a partir de uma visão escolar da história e passando a englobar, no geral, outros interesses sociais.

\footnotetext{
${ }^{1}$ Doutorado em História pela Universidade Federal Fluminense (UFF), Mestrado em História Cultural e Graduação em História (bacharelado e licenciatura) na Universidade Estadual de Campinas (UNICAMP). Professora na Universidade Federal de São Carlos (UFSCar). E-mail: vitaze@yahoo.com.br.

${ }^{2}$ Endereço de contato da autora (por correio): Universidade Federal de São Carlos (UFSCar). Rodovia Washington Luís, s/n, CEP: 13565-905, São Carlos - SP, Brasil.
} 


\title{
Crevisto
}

ISSN n² 2447-4266 Vol. 3, n. 2, Abril-Junho. 2017

DOI: http://dx.doi.org/10.20873/uft.2447-4266.2017v3n2p92

PALAVRA-CHAVE: História escolar, filme histórico, ensino de História.

\begin{abstract}
This text aims to reflect upon school History themes in the Brazilian movies throughout its course, starting from a comparison between the steps of discipline constitution and film production. However, in recente years, there has been a distancing between school History and History in the movies. The fact may be indicative that History themes in the movies have been directed to other audiences and areas besides not to be conceived from a school History's point of view in order to meet another social concerns.
\end{abstract}

KEYWORDS: History, Historical film, History teaching.

\section{RESUMEN}

Este texto pretende reflexionar sobre los temas de Historia escolar en el cine brasileño a lo largo de su curso, partiendo de una comparación entre los pasos de la constitución de la disciplina y la producción cinematográfica. Sin embargo, en los últimos años, ha habido un distanciamiento entre la historia escolar y la historia en las películas. El hecho puede ser indicativo de que los temas de Historia en el cine han sido dirigidos a otras audiencias y ámbitos dejando de ser pensada a partir de una visión escolar de la historia y pasando a englobar, no general, otros espacios sociales.

PALAVRA-CHAVE: Historia de la escuela, la historia del cine, enseñanza de la historia.

Recebido em: 24.01.2017. Aceito em: 26.03.2017. Publicado em: 01.04.2017. 


\section{Crevisto}

ISSN n² 2447-4266 Vol. 3, n. 2, Abril-Junho. 2017

DOI: http://dx.doi.org/10.20873/uft.2447-4266.2017v3n2p92

\section{Introdução}

A História Pública, como campo de abordagem tem solidificado suas bases a partir de delimitações necessárias do que seja, nas quais torna-se improdutiva a inserção de "qualquer" prática historiográfica que tenha apenas alguma relação com o "público". Assim, podemos dizer que a história pública "...é um conceito escorregadio" e, como afirma Liddington, se o conceito tornarse apenas um nome para o que já vinha sendo feito pelos historiadores pareceria perder-se a oportunidade de aperfeiçoar a prática e a de fato, promover mudanças no campo historiográfico.

Sem, no entanto, uma definição clara, mas, em busca de configuração a partir da atuação prática, podemos tomar a definição de Jill Liddington suficiente, "... a prática da história pública como sendo a apresentação popular do passado para um leque de audiências - por meio de museus e patrimônios históricos, filme e ficção histórica" (LIDDINGTON, 2011, p.34)

Assim, tomando por base a ideia da apresentação popular para um leque de audiências, proponho neste texto uma reflexão que, se não se refere a uma prática atual de história pública, pode contribuir para refletir sobre as suas dimensões relacionadas ao ensino de História e à história no cinema. Reflexão que vai de encontro à ideia de que "... o estudo de história pública está ligado a como adquirimos nosso senso de passado" (LIDDINGTON, 2011, p.34) a partir de diversos meios, e, aqui, entendo que, dentre estes meios, também estão os livros didáticos e os filmes históricos.

Se a produção profissional da história estivesse integrada ao público "em geral" e não fechada em seus próprios muros, possivelmente não teria sentido refletir sobre a necessidade de "publicizar", ou, de "abrir a cozinha" pois esta prática estaria integrada ao fazer historiográfico. Assim, pressuponho que falar 


\section{Oeveristo}

ISSN n² 2447-4266 Vol. 3, n. 2, Abril-Junho. 2017

DOI: http://dx.doi.org/10.20873/uft.2447-4266.2017v3n2p92

em "apresentação popular" de algo que é feito em algum lugar para um público que está fora deste lugar, significa a existência dos espaços de produção de saber sobre o passado. Atualmente, este espaço é, primordialmente, identificado com os programas de pós-graduação e institutos de pesquisa, mas, em outros momentos, esteve associado, por exemplo, ao Instituto Histórico Geográfico Brasileiro.

\section{História escolar, cinema brasileiro e história pública}

Quando refletimos sobre a constituição da história escolar como disciplina, O IHGB atuou de maneira significativa entre o século XIX e XX. E, podemos dizer, que, diversos autores de livros didáticos, nos "primórdios" da disciplina escolar, realizavam um movimento de diálogo entre as propostas de abordagem da História do Brasil do IHGB e sua didatização para os livros didáticos (inicialmente para alunos do Colégio Pedro II, posteriormente difundidos) e, ao mesmo tempo, pautavam a escrita dessa história a partir dos seus próprios livros didáticos (GASPARELLO, 2004), numa simbiose entre a escrita da História do Brasil e a constituição da História escolar.

A pesquisadora Maria Auxiliadora Schimdt (2009) propõe uma periodização para a História do ensino de História baseada na ideia de "código disciplinar", ou seja, o processo de construção do conhecimento escolarizado a partir dos saberes acadêmicos, em quatro fases do "Código disciplinar da História": primeira fase, a da construção (1838-1931); em seguida, a consolidação (1931-1971); depois, a crise (1971-1984) e, por último, a reconstrução (1984 -?). Essa autora constrói sua interpretação a partir de mudanças legais, ou seja, alterações nos documentos que legislavam sobre o ensino. Ela segue um caminho semelhante ao de outra pesquisadora, a 


\section{Crevisto}

ISSN n² 2447-4266 Vol. 3, n. 2, Abril-Junho. 2017

DOI: http://dx.doi.org/10.20873/uft.2447-4266.2017v3n2p92

professora Elza Nadai, que, por sua vez, privilegia três momentos importantes: introdução da disciplina História no currículo escolar (1830); criação de cursos de formação, para superar o autodidatismo (1930) e, por fim, as novas demandas pós II Guerra, nas décadas de 1960/1970.

A história do ensino de História, a partir de diversos autores, configura-se como objeto de estudo no meio acadêmico a partir da fase de reconstrução do código disciplinar, na década de 1980, em função de variados fatores (NADAl, 1993; FONSECA, 2003; SCHMIDT, 2009; CERRI, 2007; NETO e MELLO, 2016,) e, da mesma forma, o ensino de História, com enfoques múltiplos, é foco de atenção de mestrados, doutorados, tanto na área Educacional quanto na área de História. Muitos dossiês de revistas acadêmicas dedicam-se ao tema, e há, pelo menos, 70 títulos de livros (publicados a partir de 1983), dentre as quais estão obras tanto autorais quanto coletivas, que constitui esse universo do tema.

Tomando por base a periodização proposta por Schmidt, proponho um paralelo entre o ensino de História e as temáticas históricas selecionadas para serem filmadas. Para tal, a partir de um levantamento das temáticas tratadas nos filmes ao longo do último século, classifiquei em cinco fases, que, no geral, coincidem com a configuração do código disciplinar. Esses períodos seriam: uma primeira que vai de 1900 a 1958, que poderíamos chamar de primórdios do cinema caracterizado pela pouca produção; produção de filmes que estão perdidos, mas cuja temática histórica aparece em alguns filmes. A segunda fase seria de 1959 a 1979, caracterizado por um grande apelo à temática do nacional e a busca do cinema por seu público. Nesse período houve incentivos estatais para a produção de filmes com temática histórica, que coincide com a consolidação do código disciplinar de História. A fase seguinte, de 1980 a 1993, que permeia o período da redemocratização, e, no campo disciplinar, de 


\section{Qrevisto}

ISSN n² 2447-4266 Vol. 3, n. 2, Abril-Junho. 2017

DOI: http://dx.doi.org/10.20873/uft.2447-4266.2017v3n2p92

reconstrução do código disciplinar, que viria até os dias atuais.No caso da temática histórica no cinema, no entanto, proponho a divisão em dois momentos: a fase de 1996 a 2006, quando houve uma grande produção de filmes com temática histórica, e, de 2006 a 2016, que, ao contrário, com menos produções de filmes com a temática histórica, o que parece solidificar uma tendência de afastamento de uma abordagem da história identificada como "tradicional" e, portanto, identifica com a "história escolar", apesar das mudanças e propostas de mudanças curriculares no âmbito do ensino de História.

Com o movimento de mudança de regime político, ocorrido em 1889, poderíamos esperar mudanças no ensino de História. Mas, neste caso, as mudanças não foram imediatas e, ao contrário, houve muitas permanências. Apenas aos poucos que o ensino de História irá incorporar as mudanças do novo tempo. $\mathrm{Na}$ análise da pesquisadora Arlette Gasparello (2004), a produção historiográfica identificada com o ideário monarquista não é tão diferente assim da produção "republicana". Alguns autores, como João Ribeiro, em sua História do Brasil, já no período republicano, inova ao colocar "unidades temáticas" no lugar das clássicas "lições", apresentando uma lógica argumentativa. Quem será mais crítico é Pedro Couto com seus Pontos de História do Brasil. Esse livro será importante para criar interpretações críticas ao período monárquico.

Com a mudança de regime para a República, as políticas educacionais estavam voltadas para um número maior de segmentos sociais e a história atuava para inculcar valores de ordem, obediência para o progresso da Nação. Nesse aspecto, também entraria o conceito de cidadania, a partir, claro, das concepções da época. A história ensinava as tradições nacionais dos grandes homens e despertava o patriotismo. 


\section{Oevisto}

ISSN n² 2447-4266 Vol. 3, n. 2, Abril-Junho. 2017

DOI: http://dx.doi.org/10.20873/uft.2447-4266.2017v3n2p92

Nesse período, a História do Brasil esteve subordinada à história europeia, o 'berço da nação', mesmo com os debates nacionalistas da década de 1930. Essa subordinação à história europeia aprofundou-se no período republicano, continuando presente nos currículos. O processo histórico estava centrado, inicialmente, no colonizador português, e, depois, no imigrante europeu, com algumas contribuições de povos africanos e indígenas buscando criar a ideia da formação da nacionalidade a partir da contribuição das "três raças". O eurocentrismo, no entanto, do ensino de História recebeu críticas e, depois de intensos debates, foram introduzidas as histórias de outros países, tais como países da América. Mas, ainda permeava o conceito de fato histórico objetivo e neutro, sem considerar a história como uma construção social.

Essa era a única história? Não. Havia quem contestasse. Manuel Bomfim focava na mestiçagem americana e educação popular e grupos anarquistas queriam escolas libertárias. No entanto, com a centralização do poder na Era Vargas, a organização do ensino foi criando homogeneidades. No bojo do debate da Escola Nova, a disciplina de História não ficou de fora. Murilo Mendes, por exemplo, defendia, em 1935, que se estudasse história contemporânea, mais próxima da realidade dos alunos. A disciplina de história encarnava o tipo de ensino que se queria evitar: memorização sem sentido, passividade do aluno, abordagem factual, etc. No período da Era Vargas, há indícios em livros didáticos e memórias que o foco do ensino estava na memorização e na criação de "heróis nacionais".

Sobre este período, no âmbito do cinema, Jean Claude Bernardet e Alcides Freire Ramos trazem uma contribuição importante no livro, voltado para professores, intitulado "Cinema e História do Brasil".Os autores indicam a existência de filmes, a partir de notícias de jornais, que demonstram, pelo título, 


\section{Oevisto}

ISSN n² 2447-4266 Vol. 3, n. 2, Abril-Junho. 2017

DOI: http://dx.doi.org/10.20873/uft.2447-4266.2017v3n2p92

a iniciativa de abordarem assuntos da história do Brasil. São destacados os filmes Tiradentes ou o mártir da liberdade (Paulo Aliano, 1917); Grito do Ipiranga ou independência ou morte (Lambertini, 1917); Heróis Brasileiros na Guerra do Paraguai (Lambertini, 1917), todos perdidos. De acordo com Bernardet, a explicação para a escolha do tema está em seus diretores serem imigrantes italianos visando sua integração à cultura brasileira.

Nas décadas de 1930 e 1940, no período Vargas, com o processo de centralização política e busca de constituição do "nacional", período que marca o início do processo de consolidação da disciplina História, houve também o incentivo na realização de filmes educativos que pudessem promover uma "integração nacional", a partir do Instituto Nacional de Cinema Educativo (INCE), criado em 1937, onde Humberto Mauro dirigiu curtas metragens educativos e os filmes O Descobrimento do Brasil (1937) e Os Bandeirantes (1940).

Nesse projeto estavam envolvidos diversos intelectuais, dentre eles, Jonathas Serrano, autor de diversos livros sobre ensino de História, professor do Colégio Pedro II e também defensor da utilização do cinema na educação. Escreveu, junto com Francisco Venâncio, em 1929, o livro Cinema e Educação.

$\mathrm{Na}$ análise do filme Descobrimento do Brasil, Eduardo Morettin apontou para a construção de uma legitimidade discursiva a partir da citação visual de referências, tais como Afonso de Taunay, que remete ao IHGB, em busca da construção de um discurso correto a partir do lugar de onde o filme deveria falar. Nesse âmbito, Serrano estabelecera um debate sobre o tipo de filme a ser feito e a ser utilizado no ensino de História, rechaçando a história dramatizada, lançoualgumas sementes interpretativas. Humberto Mauro, nesse contexto, teve um grande desafio. 


\section{Grevisto}

ISSN n² 2447-4266 Vol. 3, n. 2, Abril-Junho. 2017

DOI: http://dx.doi.org/10.20873/uft.2447-4266.2017v3n2p92

A participação de Mauro em Descobrimento do Brasil o colocará diante de uma tarefa de difícil resolução. Em primeiro lugar, demonstrar por meio do cinema, a leitura histórica correta sobre o tema do descobrimento. Em segundo lugar, conciliar esta leitura com a tentativa de efetivar 'as esplendidas realizações apparatosas', prática comum e bem sucedida em outras cinematografias, como a americana, por exemplo, mas inédita e recheada de senões em função da já caracterizada precariedade do cinema brasileiro. (MORETTIN, 2001, p.151)

A história narrada no cinema e a história construída nos, e para, os livros didáticos, compõem uma mesma trama que configura um intrincamento que permeará a temática histórica no cinema, entre a sua afirmação e sua negação.

$\mathrm{Na}$ década de 1950, a defesa de temas históricos como fontes para o cinema aparece numa discussão sobre o nacional e o popular no cinema brasileiro, de acordo com Bernardet e Galvão (1983).Nos embates, há uma vertente que defende os temas históricos, em um viés mais popular, e, uma outra, associada aos filmes de estúdio, para quem a abordagem histórica seguiria uma visão que pode ser caracterizada como "tradicional", aquela focada nos grandes heróis. No entanto, em nenhum dos dois casos, a história está dissociada da sua versão escolar.

.... literatura, o folclore e a história devem ser as fontes do cinema
brasileiro e sugere [Nelson Pereira dos Santos] temas como: Canudos,
a Abolição da Escravatura, a Inconfidência Mineira e os Bandeirantes.
Na outra vertente ideológica, Zampari, diretor da Vera Cruz, traça
planos para 1954: faremos 'filmes completamente brasileiros e
baseados nos fatos históricos do Brasil.' Prevê um filme sobre o
Duque de Caxias, 'uma figura impressionante', outro sobre D. Pedro I,
'particularmente o lado romântico de sua vida' (BERNARDET, RAMOS,
1983, p.12).

Em 1948, o filme de Carmem Santos, fracasso de bilheteria, foi um dos poucos exemplos da década, de filme com temática histórica que seguia a 


\section{Qrevisto}

ISSN n² 2447-4266 Vol. 3, n. 2, Abril-Junho. 2017

DOI: http://dx.doi.org/10.20873/uft.2447-4266.2017v3n2p92

proposta da história escolar. Assim, nesse primeiro período, podemos contar 10 filmes, dos quais, 5 foram perdidos.

Essa promissora possibilidade de alinhamento entre a história escolar e o cinema segue uma tendência de produção cinematográfica associada a uma "história tradicional", pautada pela história escolar do período de construção do código disciplinar. No entanto, o que podemos observar nos anos seguintes, é que essa associação entre filme histórico e a história escolar do início do século não se configura como uma aliança feliz, fadada ao fracasso com o passar dos anos.

No segundo período, delimitado por mim, provisoriamente, entre 1959 e 1979, indica a tímida permanência de temas ligados a história escolar, mas, com a inserção de novas abordagens e, novos temas, com referências que se distanciam do âmbito educacional. No Cinema Novo, a temática histórica recorrente, aparece de forma diferenciada. O passado, na estética cinemanovista, é carregado de presente e de problematização.

Assim, convivem, no cinema histórico, construções visuais e narrativas chocantes: de um lado, Os Inconfidentes(Joaquim Pedro, 1972), de outro, Tiradentes, o mártir da independência. (Geraldo Vietri, 1976)

Seguindo a lógica proposta, o segundo filme poderia ser encaixado numa vertente de abordagem da história no cinema que se aproxima da histórica escolar, pelo menos, daquela presente na visão desses cineastas. No entanto, enquanto a construção do código disciplinar de História estava permeado por uma crise, na sua junção e homogeneização em Estudos Sociais, o cinema brasileiro produziu variados filmes que, cada um a seu modo, produziu narrativas sobre o passado sem, no entanto, deixar de estabelecer 


\section{Oeveristo}

ISSN n² 2447-4266 Vol. 3, n. 2, Abril-Junho. 2017

DOI: http://dx.doi.org/10.20873/uft.2447-4266.2017v3n2p92

diálogos com algum tipo de produção histórica escrita, sejam fontes históricas ou uma historiográfica popular.

Por exemplo, na construção de Inconfidentes, de acordo com Alcides Freire Ramos, houve um processo de pesquisa e, a fonte principal para o filme, os Autos da Devassa, indicam a necessidade de estabelecer um diálogo com uma história mais "legítima".

No caso do filme Como era gostoso meu francês, numa abordagem que se destaca do tradicional, o diretor tenta justificar, de certa maneira, a diferença: "Como era gostoso... é uma invenção minha, evidentemente baseada em todos os cronistas da época: Hans Staden, Jean de Lery, os jesuítas, mas basicamente é a aventura de Hans Staden. Aquele filme é uma parábola sobre a ditadura..." (SANTOS, 1998, p.16). No entanto, fica claro no filme que a relação estabelecida com a construção do passado é outra: existe um olhar crítico, desconfiado, que questiona as narrativas para construir a sua própria. Segundo Ismail Xavier, o filme de Santos incorpora a tradição das descrições "...para deslocar perspectivas, desconfiar de versões oficiais, aludir à violência recalcada por discursos civilizatórios." (XAVIER, 1998, p.167).

\footnotetext{
O filme de Nelson Pereira nos fala sobre o cinema da década de 1970 e sobre uma determinada postura frente à cena política da época e vem imbuído de ideias e propostas de transformação. Sua postura contrária ao regime estabelecido e suas propostas de mudança a partir dos "vencidos" levam-no a olhar para história como aquela escrita pelos "vencedores", sendo assim, algo a ser contestada. A história assume claramente uma relação direta com as lutas do presente.(FONSECA, 2010, p.113)
}

Glauber Rocha, um outro exemplo, propõe em seus filmes releituras e ressignificações da história. A temática do Descobrimento aparece em Terra em Transe, de forma diferente da tradicional, como escreve José Gatti: "...[o filme] 


\section{Oeveristo}

ISSN n² 2447-4266 Vol. 3, n. 2, Abril-Junho. 2017

DOI: http://dx.doi.org/10.20873/uft.2447-4266.2017v3n2p92

questiona a Carta de Caminha, rejeita a Missa de Meirelles e abre um outro modo de fazer cinema e história...". Para esse mesmo autor: "O cinema de Glauber, além de não seguir as exigências das narrativas lineares e das estratégias naturalistas, enreda e sincretiza tempos e lugares de modo a (re)situar os eventos históricos, sem pleitear qualquer autenticidade."(GATTI, p.73)

Assim, os filmes ligados ao Cinema Novo, tematizam a história numa perspectiva bastante diferente da tradicional que, apesar do distanciamento com uma história escolar tradicional, está sintonizado com mudanças do presente.

A partir da década de 1970, o Ministério da Educação incentivou a produção de filmes com temáticas históricas, do tipo escolar. O Estado tenta novamente controlar a produção de filmes desta natureza, sem, no entanto, obter um grande sucesso: o único filme realizado com o apoio governamental foi Anchieta, José do Brasil (Paulo César Saraceni, 1978). Mas a intervenção ou não do Estado não foi determinante na ideologia das abordagens históricas dos filmes, como escreve Jean Claude Bernardet. Os filmes poderiam ter formas e conteúdos totalmente de acordo com a ideologia estatal sem terem sido financiados pelo Estado, como é o caso do filme Independência ou morte (Carlos Coimbra, 1972), de acordo com Fonseca (2016). Este, depois de pronto, foi encampado pelo governo como referência para a realização de filmes deste gênero. Neste caso, a ideologia dos filmes históricos independia da interferência ou participação do Estado.

Nesse período, dos quase 30 filmes identificados com alguma referência à dinâmica do tempo, chama a atenção 3 filmes sobre a Inconfidência, 1 sobre Bandeirantes, 2 com referência ao período do "Descobrimento", 1 sobre Getúlio 


\section{Grevisto}

ISSN n² 2447-4266 Vol. 3, n. 2, Abril-Junho. 2017

DOI: http://dx.doi.org/10.20873/uft.2447-4266.2017v3n2p92

Vargas, 2 sobre escravidão e questão racial, 3 sobre revoltas e guerras. Mas, um tipo de filme que aparece nesse período, que vai ter outros exemplos em anos posteriores, são aqueles cuja temática é a criminalidade, ou a biografia de criminosos.Nesse sentido, emergem temáticas que partem de uma necessidade de compreensão do passado que não tem relação nem com a história escolar e nem com a produção historiográfica.

No terceiro período, que vai de 1980 a 1993, período que coincide com a reconstrução do código disciplinar de História, que é permeado por diversos debates sobre a volta do seu ensino bem como um acirrado debate em defesa do seu currículo, a produção cinematográfica volta-se para a temática histórica, principalmente através do gênero 'documentário' em filmes como Cabra Marcado para Morrer (Eduardo Coutinho, 1984), Guerra do Brasil (Sylvio Back, 1987), Os anos JK - uma trajetória política (Silvio Tendler, 1980).

Nesse período, nenhuma temática tradicional do cinema histórico, e grande produção voltada para pensar questões do presente. Nesse sentido, dentre os quase 40 títulos, chama a atenção que a temática da Ditadura seja tratada em 6 filmes, e, em 8 filmes há referências ao período da Era Vargas, 4 filmes que tematizam aspectos da escravidão, 3 do período democrático, 1 sobre a Guerra do Paraguai, 1 sobre Jesuítas, 1 sobre migração, 1 sobre criminalidade e algumas biografias musicais.

No final dos anos 1970, com a crise do Regime Militar e o processo de redemocratização, ficou clara a necessidade de mudanças no âmbito da abordagem escolar da História. Os debates começaram nos estados e resultou em novos programas e novas propostas, pautados pela questão do momento que era a redemocratização. Nesse debate envolveram-se professores da rede pública, imprensa, secretarias de educação, entidades. O processo gerou 


\section{Oevisto}

ISSN n² 2447-4266 Vol. 3, n. 2, Abril-Junho. 2017

DOI: http://dx.doi.org/10.20873/uft.2447-4266.2017v3n2p92

intenso debate e uma proposta demorou a ser implementada e, com isso, outros "currículos" foram sendo implementados e as editoras também adotaram outros modelos. Nesse sentido, ganham força os livros didáticos, pautados, em sua maioria, pelas propostas curriculares estaduais, com destaque para a de Minas Gerais (1986), seus princípios básicos tal como a integração entre História do Brasil e História Geral, a organização por modos de produção (das comunidades primitivas a sociedade capitalista) com termos e conceitos marxistas, como observou a pesquisadora Selva Fonseca.

Para muitos o programa satisfazia os anseios do momento num modelo de ensino democrático e participativo e, em pouco tempo, tinha a aprovação das editoras, professores, pais e alunos. Era uma proposta que respondia ao anseio de uma história mais crítica, participativa, cujo eixo de orientação estava pautado na ideia de que os homens fazem a História e produzem seu conhecimento histórico.

No entanto, programa claramente marcado pelo marxismo, acabou por construir imagens maniqueístas de contraposição entre o Estado e a burguesia, os cruéis, e os operários, dificultando a compreensão de alguns processos históricos. Nesse sentido, sentiu-se a necessidade de novos materiais didáticos. Aliado a isso, novas tendências animavam o campo da produção historiográfica, crítica do marxismo, nos anos 1990, levando a um processo de renovação pautada pela chamada "Nova História" de origem francesa.

Com maior liberdade, novas propostas surgiram. A partir desse momento, a relação entre o saber escolar e o saber acadêmico ficam cada vez mais próximos. Ou seja, o saber acadêmico, cada vez mais, passa a pautar os debates em torno do currículo escolar em História. Chegando a ser sinal de 


\section{Crevisto}

ISSN n² 2447-4266 Vol. 3, n. 2, Abril-Junho. 2017

DOI: http://dx.doi.org/10.20873/uft.2447-4266.2017v3n2p92

qualidade aqueles que conseguiam levar para a sala de aula as novidades no âmbito historiográfico.

Rapidamente a história das mentalidades e do cotidiano transformaramse em vedetes inovadoras. Com o tempo observou-se um boom editorial, principalmente com o PNLD. Além disso, os PCNs passaram a ser os norteadores dos programas e dos livros didáticos.

Apesar de, segundo Schimdt, vivermos um processo de reconstrução do código disciplinar, no âmbito escolar, na produção de filmes com temática histórica, podemos dividir os últimos vinte anos em dois períodos: de 1995 a 2006, no qual observamos a presença maior de filmes com temáticas da história escolar tradicional, e, no período seguinte, sua significativa diminuição e a consolidação de abordagens da dinâmica do tempo em outros vieses, principalmente a biografia.

Assim, no período situado entre 1995, a partir do Prêmio Resgate do Cinema Brasileiro, e 2006, a temática histórica volta a ser tratada pelo viés ficcional e algumas abordagens próximas do viés da "história escolar" aparecem em cena, como podemos perceber na tabela abaixo.

\begin{tabular}{|l|c|c|c|c|c|c|}
\hline \multicolumn{1}{|c|}{ TEMA/PERÍODO } & $\begin{array}{c}\mathbf{1 9 0 0 -} \\
\mathbf{1 9 5 8}\end{array}$ & $\begin{array}{c}\mathbf{1 9 5 9 -} \\
\mathbf{1 9 7 9}\end{array}$ & $\begin{array}{c}\mathbf{1 9 8 0} \\
\mathbf{1 9 9 3}\end{array}$ & $\begin{array}{c}\mathbf{1 9 9 4 -} \\
\mathbf{2 0 0 6}\end{array}$ & $\begin{array}{c}\mathbf{2 0 0 7 -} \\
\mathbf{2 0 1 6}\end{array}$ & total \\
\hline BANDEIRAS & 2 & 1 & & 1 & & 4 \\
\hline DESCOBRIMENTO/CONTATO & 1 & 2 & & 3 & 2 & 8 \\
\hline GUERRA DO PARAGUAI & 1 & & 1 & 1 & & 3 \\
\hline INCONFIDÊNCIA & 2 & 3 & & 1 & & 6 \\
\hline INDEPENDÊNCIA & 1 & & & 1 & & 2 \\
\hline JESUÍTAS & 1 & 1 & 1 & & & 3 \\
\hline CONTESTADO & & 1 & & & 1 & 2 \\
\hline CORONELISMO & & 1 & & 1 & & 2 \\
\hline ERA VARGAS & & 1 & 8 & 3 & 2 & 14 \\
\hline $\begin{array}{l}\text { ESCRAVIDÃO/QUESTÃO } \\
\text { RACIAL }\end{array}$ & & 2 & 5 & 3 & 4 & 14 \\
\hline REVOLTAS/GUERRAS & & 1 & & 5 & 2 & 8 \\
\hline
\end{tabular}




\section{Obevisto}

ISSN n² 2447-4266 Vol. 3, n. 2, Abril-Junho. 2017

DOI: http://dx.doi.org/10.20873/uft.2447-4266.2017v3n2p92

\begin{tabular}{|c|c|c|c|c|c|c|}
\hline NACIONAL /NAÇÃO & & 1 & & 5 & 2 & 8 \\
\hline NAZISMO/II GUERRA & & 1 & 1 & & 5 & 7 \\
\hline QUESTAO INDÍGENA & & 4 & 1 & 4 & 4 & 13 \\
\hline CRIMINALIDADE & & & 1 & 2 & 5 & 8 \\
\hline DITADURA & & & 6 & 9 & 18 & 33 \\
\hline MIGRAÇÃO & & & 1 & 2 & 2 & 5 \\
\hline PERIODO DEMOCRÁTICO & & & 3 & & 1 & 4 \\
\hline REDEMOCRATIZAÇÃO & & & 1 & & 1 & 2 \\
\hline RELIGIOSIDADE & & & 2 & 2 & 2 & 6 \\
\hline BIOGRAFIA & & & & 16 & 49 & 65 \\
\hline COTIDIANO & & & & & 4 & 4 \\
\hline TOTAL: & 8 & 19 & 31 & 59 & 104 & \\
\hline
\end{tabular}

Tabela 1 - Temáticas relacionadas à dinâmica do tempo, abordadas no Cinema Brasileiro, por períodos. Elaboração própria

Durante os últimos 20 anos, foi possível identificar em torno de 240 filmes, entre ficções e documentários cuja temática tem alguma relação com o passado, ou, com a dinâmica do tempo na interface entre passado e presente. Observamos que nesse universo, $60 \%$ dos filmes são documentários, dos mais variados tipos e $40 \%$ adotam a estética ficcional.

\section{Considerações Finais}

Nesse montante, é interessante observar que $40 \%$ dos filmes abordam diretamente uma biografia (documentários e ficções), dentre as quais, mais de $50 \%$ estão relacionadas a artistas, sejam escritores, atores, pintores, músicos e cineastas. Assim, podemos considerar que grande parte dessa produção voltada para pensar a dinâmica do tempo tem favorecido a reflexão sobre trajetórias de pessoas ligadas à dimensão artística. Dessas biografias, apenas $12 \%$ tem alguma relação com uma "personalidade histórica" que faça parte da dimensão escolar, em alguma medida, tal como Getúlio Vargas, Tiradentes, Anita Garibaldi, Aleijadinho, dentre outros. Essa preferência pela temática artística é 


\section{Crevisto}

ISSN n² 2447-4266 Vol. 3, n. 2, Abril-Junho. 2017

DOI: http://dx.doi.org/10.20873/uft.2447-4266.2017v3n2p92

muito interessante, e é visível a predileção pela trajetória de músicos que engloba $24 \%$ do total das biografias.

Dentre as temáticas mais abordadas pelos filmes a música ocupa $15 \%$ do total, seguido da Ditadura Militar, com $12 \%$ dos temas, com em torno de 30 produções. A temática da guerra, dentre a Segunda Guerra Mundial, e conflitos armados no Brasil, somam 15 produções, ou seja, $6 \%$ das produções sendo o terceiro tema mais abordado. A questão indígena, temas ligados a política e ao futebol têm em torno de 10 produções cada, ou seja, $4 \%$ do total. Outros temas aparecem com a mesma incidência, são eles questões do cotidiano, de identidade nacional, questões sobre o contato entre culturas no século $\mathrm{XVI}$, Nazismo relacionado a sobreviventes, reflexões sobre cidades e criminalidade.Percebe-se que uma visão tradicional é pouco contemplada na produção cinematográfica de longas metragens.

Refletindo no entanto, sobre os últimos dez anos, é bastante significativo que a temática da Ditadura Militar tenha um grande número de filmes, bem como a escolha pelas biografias e, principalmente, o número de biografias de pessoas "comuns". O cinema parece libertar-se, na abordagem da temática do passado, daquela história escolar, identificada com o "tradicional" na produção de temáticas que parecem surgir a partir de necessidades do presente e não para suprir alguma carência em termos de ensino de História. Podemos dizer que a temática histórica no cinema vem sendo ampliada para outros públicos e outros espaços deixando de ser pensada apenas a partir de uma visão escolar da história e passando a englobar outros interesses sociais.

\section{Referências}




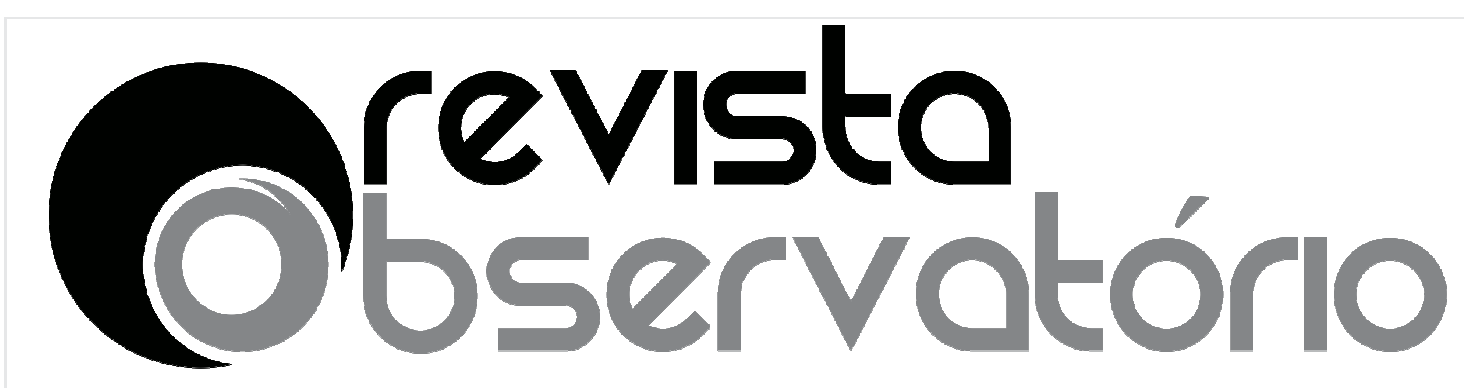

ISSN n² 2447-4266 Vol. 3, n. 2, Abril-Junho. 2017

DOI: http://dx.doi.org/10.20873/uft.2447-4266.2017v3n2p92

ALIANO, Paulo. FELICE, Perassi. Tiradentes ou o mártir da liberdade. Perassi Felice, Paulo Aliano, Aliano Filmes, São Paulo, 1917. Longa-metragem, Ficção, $35 \mathrm{~mm}$, silencioso.

ANDRADE, Joaquim Pedro. Os Inconfidentes. Joaquim Pedro de Andrade, Brasil, Itália, 1972, colorido, 100 min, sonoro.

BACK, Sylvio. Guerra do Brasil.Sylvio Back, 1987. Longa-metragem, 83 min, documentário, sonoro.

BERNARDET, Jean Claude e GALVÃO, Maria Rita.Cinema: repercussões em caixa de eco ideológica. São Paulo: Brasiliense, Rio de Janeiro: Embrafilme, 1983.

BERNARDET, Jean Claude e RAMOS, Alcides Freire. Cinema e História do Brasil. São Paulo: Contexto, 1988.

CERRI, Luís Fernando. "Uma proposta de mapa do tempo para artesãos de mapas do tempo: historia do ensino de história e didática da história" in: MONTEIRO, Ana M.; GASPARELLO, Arlete M; MAGALHÃES, Marcelo S. (org). Ensino de história: sujeitos, saberes e práticas. Rio de Janeiro: Mauad $X$ : FAPERJ, 2007. pp.59-72

COIMBRA, Carlos. MASSAINI, Oswaldo. Independência ou morte. Carlos Coimbra, Cinedistri, São Paulo, 1972. Longa-metragem, 35 mm, 108 min, sonoro.

COUTINHO, Eduardo. Cabra Marcado para Morrer.Eduardo Coutinho, 1984. Longa metragem, p\&b/colorido, 119 min, sonoro.

FONSECA, Thaís Nívia de Lima. História \& Ensino de História. Belo Horizonte: Autêntica, 2003 


\section{Oevisto}

ISSN n² 2447-4266 Vol. 3, n. 2, Abril-Junho. 2017

DOI: http://dx.doi.org/10.20873/uft.2447-4266.2017v3n2p92

FONSECA, Vitória Azevedo da. "Quando as contradições são conciliadas e a história "oficial" vai além do controle de estado". Temática.Ano XII, n. 03. Março/2016, pp.29-45

FONSECA, Vitória Azevedo da. "Eus e olhares sobre os outros: relatos de Hans Staden e suas releituras cinematográficas", Revista Outros Tempos, ano 7, n. 9. p. 100-115, jul. 2010.

GASPARELLO, Arlette Medeiros. Construtores de identidades: a pedagogia da nação nos livros didáticos da escola secundária brasileira. São Paulo: Iglu, 2004.

GATTI, José. "(Re)descobrimentos do Brasil" In.:Cinemais Revista de cinema e outras questões audiovisuais. Número 16 - março/abril de 1999 -Ministério da Cultura/Sec. Desenvolvimento do Audiovisual - pp.59-74.

LAMBERTINI, Giorgio. Grito do Ipiranga ou independência ou morte, Giorgio Lambertini, São Paulo, Ipiranga Filmes, 1917. Longa-metragem, 35 mm, 145 min, silencioso.

LAMBERTINI, Giorgio. Heróis Brasileiros na Guerra do Paraguai.Família Lambertini, São Paulo, Ipiranga Filmes, 1917. Longa-metragem, 35 mm, silencioso.

LIDDINGTON, Jill. "O que é história pública" in: ALMEIDA, Juniele Rabelo e ROVAI, Marta G.O (org). Introdução à história pública. São Paulo: Letra e Voz, 2011, pp.31-52

MAURO, Humberto. O Descobrimento do Brasil . Humberto Mauro, São Paulo, DFB, 1937. Longa-metragem, $35 \mathrm{~mm}, 60 \mathrm{~min}$, sonoro.

MAURO, Humberto. Os Bandeirantes. Humberto Mauro, São Paulo, 1940. Longa-metragem, $35 \mathrm{~mm}$, sonoro. 


\section{Crevisto}

ISSN n² 2447-4266 Vol. 3, n. 2, Abril-Junho. 2017

DOI: http://dx.doi.org/10.20873/uft.2447-4266.2017v3n2p92

MORETTIN, Eduardo Victorio. Cinema e história: uma análise do filme "Os bandeirantes". (Dissertação de Mestrado), São Paulo: ECA/USP, 1994.

Os limites de um projeto de monumentalização cinematográfica: análise do filme Descobrimento do Brasil (1937), de Humberto Mauro. (Tese de doutorado) São Paulo, 2001.

NADAl, Elza. O ensino de história no Brasil: trajetória e perspectiva. RevistaBrasileirade História, São Paulo, v. 13, n. 25/26, set. 92/ago. 93, p. 143162.

NETO, Antônio S. A.; MELLO, Paulo E. D. "Memórias e escritos do ensino de história: apontamentos iniciais" in: MOLINA, Ana H.; FERREIRA, Carlos A. L. Entre textos e contextos: caminhos do ensino de história. Curitiba: CRV, 2016, p.17-37

SANTOS, Nelson Pereira dos. MANFRED, Klaus. Como era gostoso meu francês. Nelson Pereira dos Santos, Condor Filmes, Rio de Janeiro, 1971. Longametragem, $35 \mathrm{~mm}$, colorido, $84 \mathrm{~min}$, sonoro.

SANTOS, Nelson Pereira. "Campo e contracampo - A tela caleidoscópica de Nelson Pereira dos Santos". Revista Sexta Feira, n ${ }^{\circ} .3$ - fronteiras, São Paulo: Pletora Editora, outubro 1998

SARACENI, Paulo César, PALLUCH, André. Anchieta, José do Brasil. Paulo César Saraceni. Embrafilme, Sant'Anna Produtora Brasileira de Filmes Ltda, Rio de Janeiro, 1977. Longa-metragem, $35 \mathrm{~mm}$, colorido, $150 \mathrm{~min}$, sonoro.

SCHMIDT, Maria a. "Histórias do ensino de História" in: Ensinar História. São Paulo: Scipione, 2009, pp. 11-31

TENDLER, Silvio. Os anos JK - uma trajetória política .Silvio Tendler, Rio de Janeiro, 1980. Documentário, p\&b/colorido, 110 min, sonoro. 


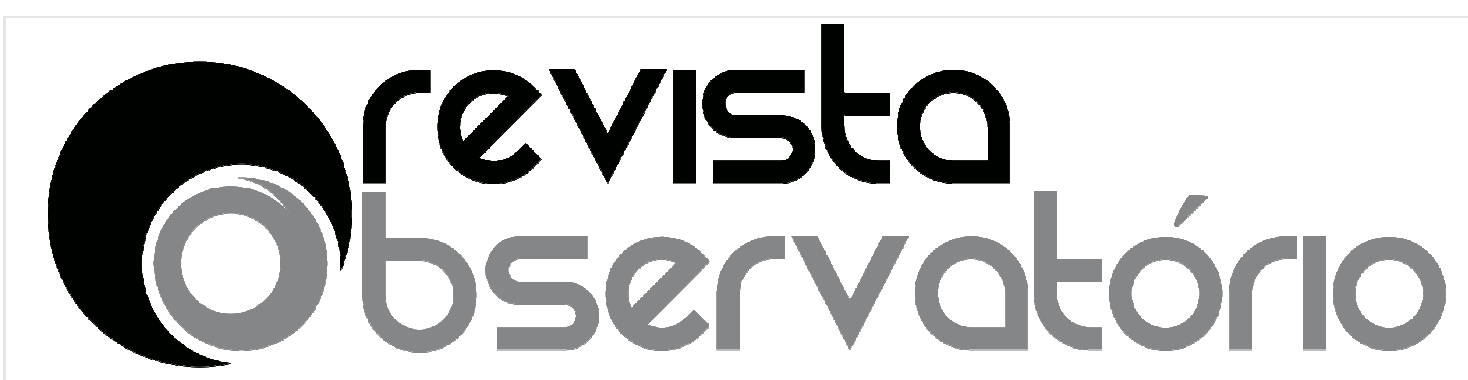

ISSN n² 2447-4266 Vol. 3, n. 2, Abril-Junho. 2017

DOI: http://dx.doi.org/10.20873/uft.2447-4266.2017v3n2p92

VIETRI, Geraldo. Tiradentes, o mártir da independência. Geraldo Vietri, São Paulo, 1976. Longa-Metragem, colorido, $90 \mathrm{~min}$, sonoro.

XAVIER, Ismail. "Eldorado como inferno. Cinema Novo, Pós-Cinema Novo e as apropriações do imaginário do Descobrimento". Revista Sexta Feira, n ${ }^{\circ} .3$ fronteiras, São Paulo: Pletora Editora, outubro 1998. 